Dental Therapist Journal

Vol. 3, No. 2, November 2021, pp. 72-77

P-ISSN 2715-3770, E-ISSN 2746-4539

Journal DOI: https://doi.org/10.31965/DTJ

Journal homepage: http://jurnal.poltekeskupang.ac.id/index.php/DTJ

\title{
Hubungan Pengetahuan dengan Pola Asuh Authoritative dalam Upaya Pencegahan Karies Gigi Anak Di Remote Area
}

\author{
Leny Marlina A. Pinat ${ }^{a, 1^{\star}}$, Merniawati Sherly Eluama ${ }^{a}$, Mery Novaria Pay ${ }^{a}$ \\ a Jurusan Kesehatan Gigi, Poltekkes Kemenkes Kupang, Indonesia. \\ 1erlanggasteven78@gmail.com* \\ *korespondensi penulis
}

\begin{tabular}{l}
\hline Informasi artikel \\
\hline Sejarah artikel: \\
Diterima 4 November 2021 \\
Disetujui 30 November 2021 \\
Dipublikasikan 30 November 2021
\end{tabular}

\section{ABSTRAK}

Karies gigi merupakan penyakit yang memiliki prevalensi tinggi dan menjadi masalah utama kesehatan masyarakat di seluruh dunia terutama pada anak-anak. Pemeliharaan kesehatan gigi anak melibatkan interaksi antara anak, orang tua dan dokter gigi. Pengetahuan dan perilaku ibu dalam upaya pemeliharaan kesehatan gigi memberi pengaruh signifikan terhadap perilaku

Kata kunci:

Pengetahuan

Pola Asuh Authoritative

Karies Gigi Anak

Remote Area anak. Pola asuh authoritative (ramah, kontrol tinggi) memiliki komunikasi dua arah dengan tidak terlalu keras dalam pola pengasuhan tetapi juga tidak lepas kontrol pada anak. Tujuan penelitian ini merupakan untuk hubungan antara pengetahuan dan tipe pola asuh authoritative dalam upaya pencegahan karies gigi anak sekolah dasar di remote area. Penelitian ini merupakan penelitian Cross-Sectional, dilakukan pada ibu anak usia 6-9 tahun di Desa Oelnaineno Kecamatan Takari Kabupaten Kupang. Jumlah sampel sebanyak $40 \mathrm{ibu}$, prosedur pengambilan sampel dilakukan dengan teknik simple random sampling. Data diambil melalui metode wawancara dengan kuesioner yang berisi pertanyaan untuk mengukur pengetahuan dan tipe pola asuh authoritative dalam upaya pencegahan karies gigi anak sekolah dasar. Hasil penelitian dianalisis secara statistik menggunakan uji Regresi Logistik Multi nominal dengan nilai kemaknaan yaitu nilai $p<0,05$. Terdapat hubungan yang signifikan antara pengetahuan dan tipe pola asuh authoritarian dengan signifikansi 0,042 . Pola asuh ibu dipengaruhi oleh pengetahuan dan akan berdampak pada anak. Ibu yang berpengetahuan baik menerapkan pola asuh tipe authoritative dan angka karies anak rendah dibandingkan tipe yang lain. Ada hubungan antara pengetahuan dan tipe pola authoritative ibu dalam upaya pencegahan karies gigi anak sekolah dasar di remote area.

Keyword:

Knowledge

Authoritative Parenting

Child Dental Caries

Remote Area

\begin{abstract}
The Relationship of Knowledge with Authoritative Parenting in Efforts to Prevent Child Dental Caries in Remote Areas. Dental caries is a disease that has a high prevalence and is a major public health problem worldwide, especially in children. Maintenance of children's dental health involves interaction between children, parents, and dentists. Mothers' knowledge and behavior in efforts to maintain dental health have a significant influence on children's behavior. Authoritative parenting (friendly, high control) has twoway communication with not too hard in parenting but also not out of control on children. The purpose of this study was to determine the relationship between knowledge and the type of authoritative
\end{abstract}


parenting in an effort to prevent dental caries in elementary school children in remote areas. This study is a cross-sectional study, conducted on mothers of children aged 6-9 years in Oelnaineno Village, Takari District, Kupang Regency. The number of samples was 40 mothers, the sampling procedure was carried out by simple random sampling technique. Data were collected through interviews with questionnaires containing questions to measure knowledge and types of authoritative parenting in an effort to prevent dental caries in elementary school children. The results of the study were statistically analyzed using the Multi nominal Logistics Regression test with a significance value of $p<0.05$. There is a significant relationship between knowledge and the type of authoritarian parenting with a significance of 0.042 . Mother's parenting is influenced by knowledge and will have an impact on children. Mothers who have good knowledge apply authoritative parenting styles and child caries rates are low compared to other types. There is a relationship between knowledge and type of mother's authoritative pattern in efforts to prevent dental caries in elementary school children in remote areas.

Copyright@ 2021 Dental Therapist Journal.

\section{PENDAHULUAN}

Pemeliharaan kesehatan gigi anak melibatkan interaksi antara anak, orang tua dan dokter gigi. Sikap dan perilaku orang tua, terutama ibu, dalam pemeliharaan kesehatan gigi memberi pengaruh signifikan terhadap perilaku anak. Pemeliharaan gigi anak harus dilakukan sejak dini mulai dari gigi sulung sampai pergantian gigi tetap. Orang tua harus memberikan perhatian serius pada anak karena pertumbuhan gigi permanen anak ditentukan oleh kondisi gigi sulung anak (Sufia, et al., 2011; Ingle, et al., 2014; Rahayu \& Santoso, 2013).

Karies gigi belum di jadikan prioritas oleh orang tua dalam menjaga kesehatan gigi anak, salah satu studi yang dilakukan oleh Puspitoningsih, et al., menunjukkan sebanyak $64 \%$ ibu mengatakan anaknya mengalami karies gigi. Ibu menganggap karies bukan masalah yang serius bagi kesehatan gigi anak, sehingga tidak memeriksakan kesehatan gigi anak ke puskesmas atau dokter gigi dan anak tidak diajarkan untuk menggosok gigi 2 kali sehari (Puspitoningsih, et al., 2012).

Pola asuh orang tua memiliki hubungan penting sebagai prediktor perkembangan anak. Law mendefinisikan tiga jenis pola asuh orang tua yakni authoritative, authoritarian, dan permissive. Pola asuh authoritarian (kontrol tinggi, kurang ramah). Pola asuh authoritative (ramah, kontrol tinggi). Pola asuh permissive (terlalu ramah, sedikit kontrol). Aminabadi mengemukakan bahwa pola asuh permissive dan authoritarian berhubungan dengan perilaku yang jelek dalam kesehatan mulut dibanding dengan pola asuh authoritative (Law, 2007; Aminabadi \& Farahani, 2008).

Pengetahuan merupakan salah satu faktor yang mempengaruhi pola asuh ibu. Pengetahuan mengenai kesehatan gigi anak menjadi hal keharusan bagi seorang ibu demi perkembangan dan pertumbuhan gigi-geligi anak yang baik. Pengetahuan juga dipengaruhi beberapa hal yaitu usia, pendidikan, status sosial ekonomi, pengalaman, informasi media massa dan lingkungan. Ibu yang tahu tentang karies gigi (penyebab dan cara pencegahan) membuat ibu berpikir dan berusaha agar anak tidak terkena penyakit gigi dan mulut. Ibu akan membimbing, mendidik dan mengawasi anak dengan cara yang benar dan mengambil tindakan tepat untuk mencegah terjadinya karies gigi pada anak (Haeriyah, 2013; Sharma, et al., 2015; Nurafifah, 2013). Tujuan penelitian adalah untuk menganalisis hubungan pengetahuan dan tipe pola asuh authoritative dalam upaya pencegahan karies gigi anak sekolah dasar di remote area. 


\section{METODE PENELITIAN}

Jenis penelitian ini adalah cross sectional. Penelitian dilakukan pada 40 ibu di Desa Oelnaineno. Pengambilan sampel dilakukan secara simple random sampling. Kriteria sampel yaitu lbu anak usia 6-9 tahun yang tinggal di Desa Oelnaineno dan mengasuh anaknya sendiri. Metode pengumpulan data melalui wawancara dengan menggunakan kuesioner. Instrument pengetahuan terdiri dari 10 pertanyaan yang berisi tentang karies gigi. Jawaban benar diberi nilai 1 dan salah nilai 0 . Klasifikasi skor pengetahuan dibedakan menjadi 2 yaitu skor $\geq 50 \%$ kategori baik dan skor $<50 \%$ kategori buruk. ${ }^{10}$ Sedangkan pola asuh authoritative 6 pernyataan.

Analisis data untuk menggambarkan tingkat pengetahuan responden dan pola asuh menggunakan analisis univariat, Untuk menganalisis hubungan antara pengetahuan dan pola asuh ibu menggunakan analisis bivariat dengan uji regresi logistik multi nominal. Nilai kemaknaan uji ini apabila nilai $p<0,05$ (tingkat kepercayaan 95\%).

\section{HASIL DAN PEMBAHASAN}

Table 1. Distribusi responden berdasarkan umur ibu.

\begin{tabular}{lcrr}
\hline $\begin{array}{l}\text { Kelompok umur } \\
\text { (Tahun) }\end{array}$ & $\mathbf{N}$ & Presentasi & Rata-rata \\
\hline $26-45$ & 34 & 85 & 35.50 \\
$45-65$ & 6 & 15 & 53.83 \\
\hline
\end{tabular}

Tabel 1 menunjukkan bahwa umur responden yang paling banyak berada pada kelompok umur $26-45$ tahun yaitu sebanyak 34 orang (85\%), dan yang paling sedikit berada pada kelompok umur 46-65 tahun yaitu sebanyak 6 orang (15\%).

Tabel 2. Distribusi responden berdasarkan pendidikan terakhir ibu.

\begin{tabular}{lrr}
\hline Pendidikan Ibu & Jumlah & Presentasi (\%) \\
\hline Tidak sekolah & 1 & 2,5 \\
SD & 33 & 82,5 \\
SLTP & 3 & 7,5 \\
SLTA & 3 & 7,5 \\
Jumlah & 40 & 100 \\
\hline
\end{tabular}

Tabel 2 menunjukkan bahwa pendidikan responden yang paling banyak adalah SD yaitu sebanyak 33 orang $(82,5 \%)$, dan yang paling sedikit adalah Tidak Sekolah yaitu sebanyak 1 orang $(2,5 \%)$.

Tabel 3. Distribusi responden berdasarkan pekerjaan ibu.

\begin{tabular}{lrr}
\hline Pekerjaan lbu & Jumlah & Presentasi (\%) \\
\hline Ibu Rumah Tangga & 40 & 100 \\
Jumlah & 40 & 100 \\
\hline
\end{tabular}
$(100 \%)$.

Tabel 4. Distribusi responden berdasarkan urutan kelahiran anak.

\begin{tabular}{lrr}
\hline Urutan Kelahiran & Jumlah & Presentasi (\%) \\
\hline$<2$ & 18 & 45 \\
$>2$ & 22 & 55 \\
Jumlah & 40 & 100 \\
\hline
\end{tabular}

Tabel 4 menunjukkan bahwa mayoritas ibu telah memiliki anak lebih dari 2 orang yakni sebanyak 22 orang (55\%).

Tabel 5. Hasil uji analisis regresi logistik multi nominal Hubungan antara pengetahuan dengan pola asuh authoritative.

\begin{tabular}{lcr}
\hline Variabel Independen & $\begin{array}{c}\text { Variabel } \\
\text { Dependen }\end{array}$ & sig \\
\hline Pengetahuan & Authoritative & 0,042 \\
\hline
\end{tabular}




\section{$P<0,05$ : bermakna}

Data hasil penelitian ini menunjukkan bahwa usia ibu anak sekolah dasar mayoritas berusia antara 25-39 tahun yaitu sebanyak 25 orang (62,5\%). Danang mengatakan bahwa usia terlalu muda atau terlalu tua menyebabkan peran pengasuhan orang tua menjadi kurang optimal, karena untuk dapat menjalankan peran pengasuhan secara optimal diperlukan kekuatan fisik dan psikososial. Ibu usia 25-39 tahun telah mencapai kematangan dalam berfikir dan bersikap sehingga dapat mendidik dan mengasuh anak sesuai persepsi pengasuhan yang benar dan anak mampu mencapai tahap perkembangan sesuai dengan masanya (Suseno, 2010).

Responden dalam penelitian ini adalah ibu rumah tangga. Pendidikan ibu mayoritas lulusan sekolah dasar sebanyak 33 orang $(82,5 \%)$ ini menunjukkan bahwa ibu di Desa Oelnaineno berpendidikan rendah.

Faktor lain yang berperan dalam pengasuhan orang tua adalah jumlah anak. Sebanyak $55 \%$ ibu di Desa Oelnaineno memilki jumlah anak lebih dari 2 orang. Supartini mengatakan bahwa orang tua yang mempunyai pengalaman sebelumya dalam merawat anak akan lebih siap menjalankan peran pengasuhan, dan mampu mengamati tanda-tanda pertumbuhan dan perkembangan anak dengan baik (Supartini, 2004).

Berdasarkan data dari hasil penelitian di Desa Oelnaineno diketahui bahwa pengetahuan memiliki hubungan yang signifikan dengan pola asuh ibu dengan signifikansi 0,042 . Sejalan dengan beberapa peneliti sebelumnya yang mengatakan bahwa pengetahuan atau kognitif merupakan domain yang sangat penting dalam membentuk tindakan seseorang (Overt Behavior), perilaku yang didasari oleh pengetahuan akan lebih melekat dari pada perilaku yang tidak didasari oleh pengetahuan (Warni, 2009; Amin, et al., 2014).

Beberapa peneliti juga mengatakan bahwa apabila seseorang memiliki pengetahuan yang baik maka tindakan akan berbanding lurus dengan pengetahuan. Perilaku ibu dipengaruhi oleh pengetahuan dan akan berdampak langsung pada anak. Perhatian orang tua sangat berhubungan signifikan dengan pengetahuan tentang karies pada anak dan sikap dari tahu orang tua dapat mengontrol kebiasaan anak. Ibu yang tahu tentang kesehatan gigi dan mulut akan mengajari anaknya sedini mungkin melalui pola pengasuhan (Abiola, et al., 2009; Çolakoğlu, N., \& Has, E., 2015).

Ibu dengan pengetahuan baik dan menggunakan pola asuh authoritative akan lebih baik dalam menjaga kesehatan gigi anak , Senada dengan beberapa peneliti yang mengatakan bahwa lbu yang berpengetahuan baik dengan tipe pola asuh authoritative lebih terampil membimbing anak dalam upaya pencegahan karies gigi dan dapat menurunkan karies gigi pada anak. Pola asuh ibu merupakan faktor penentu untuk mengatasi gaya dan perilaku anak. Pengetahuan ibu yang merupakan orang terdekat anak dalam pemeliharaan kesehatan memberikan pengaruh signifikan terhadap sikap dan perilaku anak. Semakin baik pengetahuan ibu tentang kesehatan gigi dan mulut, semakin baik kesehatan gigi dan mulut anak (Hooley, et al., 2012; Bazorgmehr, 2013).

Hal ini berbeda dengan beberapa peneliti yang mengatakan bahwa pengetahuan yang baik tidak selalu berbanding lurus dengan pola pengasuhan yang baik. Responden yang memiliki pengetahuan baik belum tentu memiliki sikap dan tindakan yang baik untuk mengaplikasikan pengetahuannya menjadi tindakan pemeliharaan kesehatan gigi dan mulut (Sogi, et al., 2016; Seran, et al., 2013).

Ibu dengan pengetahuan yang buruk dan kurang informasi tentang kesehatan gigi dan mulut akan berperilaku negatif terhadap kesehatan gigi. Sejalan dengan beberapa peneliti yang mengatakan bahwa ibu dengan pengetahuan yang rendah dipengaruhi oleh sikap dan karakteristik dari keluarga yang berpenghasilan rendah, kurangnya kepedulian dari orang tua, kurangnya informasi, orang tua lebih fokus pada hal mencari nafkah dari pada berkomunikasi dengan anak dan pola asuh ini dianggap dapat mengganggu pertumbuhan anak. Orang tua di Cina, Hongkong, Amerika, Eropa, dan Australia cenderung berpengetahuan rendah sehingga mempengaruhi kesehatan gigi anak mereka. Pola asuh ibu merupakan faktor penentu untuk mengatasi gaya anak-anak, dan perilaku anak (Howenstein, 2014; Heriyanto, et al., 2004; Mitakul, et al., 2012; Mohammadi, et al., 2015). 
Ibu memiliki pengetahuan buruk, disebabkan karena beberapa faktor yaitu keterbatasan mengakses informasi tentang kesehatan gigi dan mulut terutama karies gigi, faktor tempat tinggal yang jauh dari kota, jauh dari fasilitas umum, kesibukan responden membantu suami mencari nafkah, faktor budaya yang meyakini bahwa menginang dapat membuat gigi tidak berlubang dan mulut segar, membuat responden merasa bahwa penyakit gigi dan mulut bukan merupakan penyakit yang harus segera diobati. Masyarakat masih menggunakan pengobatan tradisional dengan daun-daunan maupun akar-akaran yang diambil di hutan untuk menyembuhkan penyakit termasuk penyakit gigi dan mulut.

Sejalan dengan beberapa peneliti yang mengatakan bahwa pengetahuan yang buruk di daerah pedesaan disebabkan karena kurangnya akses informasi tentang kesehatan gigi dan mulut sehingga berdampak pada peningkatan penyakit karies gigi pada anak usia sekolah. Orang tua perlu mengetahui dan mengajarkan hal hal yang baik pada anak, serta melatih anak sejak dini untuk merawat gigi sendiri. Orang tua yang memiliki pengetahuan rendah tentang pencegahan karies gigi, cenderung kurang memperhatikan kesehatan gigi dan mulut anak sehingga dapat menyebabkan terjadinya karies gigi (Worang, et al., 2014; Sanders, \& Morawska, 2005; Bezrukova \& Valentina., 2005).

\section{KESIMPULAN}

Terdapat hubungan yang signifikan antara pengetahuan dan pola asuh authoritative dalam upaya pencegahan karies gigi anak skolah dasar di remote area, ibu dengan pengetahuan yang baik menerapkan pola asuh authoritative dalam mencegah karies gigi anak.

\section{DAFTAR PUSTAKA}

Abiola Adeniyi, A., Eyitope Ogunbodede, O., Sonny Jeboda, O., \& Morenike Folayan, O. (2009). Do maternal factors influence the dental health status of Nigerian pre-school children?. International Journal of Paediatric Dentistry, 19(6), 448-454.

Amin, M., Nyachhyon, P., Elyasi, M., \& Al-Nuaimi, M. (2014). Impact of an oral health education workshop on parents' oral health knowledge, attitude, and perceived behavioral control among African immigrants. Journal of Oral Diseases, 2014.

Aminabadi, N. A., \& Farahani, R. M. (2008). Correlation of parenting style and pediatric behavior guidance strategies in the dental setting: preliminary findings. Acta Odontologica Scandinavica, 66(2), 99-104.

Bezrukova, O., \& Samoylova, V. (2015). The Authoritarian Syndrome in Attitudes and Educational Practices of Russian Parents. Procedia-Social and Behavioral Sciences, 165, 234-240.

Bozorgmehr, E., Hajizamani, A., \& Malek Mohammadi, T. (2013). Oral health behavior of parents as a predictor of oral health status of their children. International Scholarly Research Notices, 2013.

Çolakoğlu, N., \& Has, E. (2015). The Evaluation of the Effects of Socio-Demographic Factors on Oral and Dental Health: A Study on the Ages 6.-12. Procedía-social and behavioral sciences, 195, $1278-1287$.

Haeriyah. (2013). Tingkat kepedulian orangtua terhadap pemeliharaan kesehatan gigi dan mulut anak usia 6-36 bulan di Kelurahan Tamalanrea Makasar. Skripsi. Makassar: Fakultas Kedokteran Gigi Universsitas Hasanudin.

Heriyanto, Yonan \& Sriyono, N. W. (2004). Pengetahuan, persepsi dan sikap terhadap kesehatan gigi pada siswa tunanetra di panti sosial Bina Netra (PSBN) Wyata Bandung. Tesis. Yogyakarta: Magister Ilmu Kedokteran, Universitas Gadjah Mada.

Hooley, M., Skouteris, H., Boganin, C., Satur, J., \& Kilpatrick, N. (2012). Parental influence and the development of dental caries in children aged 0-6 years: a systematic review of the literature. Journal of dentistry, 40(11), 873-885.

Howenstein, J. L. (2014). Correlating Parenting Styles with the Child's Caries and Behavior in the Dental Office. Thesis. Ohio State University.

Ingle, N. A., Dubey, H. V., Kaur, N., \& Gupta, R. (2014). Prevalence of dental caries among school children of Bharatpur city, India. Journal of International Society of Preventive \& Community Dentistry, 4(1), 52. 
Law, C. S. (2007). The impact of changing parenting styles on the advancement of pediatric oral health. J Calif Dent Assoc, 35(3), 192-7.

Mitakul K, Laovoravit V, Vanichanuwat V, Charatchaiwanna C, Charatchaiwanna A, dan Bunpradit W. 2012. Factors associated with parent capability on child's oral health care. Southeast Asian J Trop Med Public Health, 43(1), 249-255.

Mohammadi, S. N., Prashant, G. M., Kumar, P. N., Sushanth, V. H., \& Imranulla, M. (2015). Dental caries status in 6-14-year-old schoolchildren of rural Channagiri, Davangere: A cross-sectional survey. Journal of Indian Association of Public Health Dentistry, 13(4), 389.

Nurafifah D. (2013). Hubungan perilaku pencegahan karies gigi dan kejadian karies gigi pada anak di dusun Sumber panggang Desa Lopang Kecamatan Kembangbahu Kabupaten Lamongan. SURYA. (1)14, 51-57.

Puspitoningsih N, Safitri W \& Istiningtyas A. (2012). Persepsi ibu tentang karies gigi TK Dharma Wanita Kecamatan Kemusu Boyolali. Surakarta: Program Studi Keperawatan STIKES Kusuma Husada.

Rahayu, T. U., \& Santoso, O. (2013). Pengaruh Edukasi Menggunakan Kika (Kartu Indikator Karies Anak) Terhadap Perilaku lbu Tentang Pencegahan Karies Gigi Sulung Di Kelurahan Randusari Semarang. Skripsi. Semarang: Fakultas Kedokteran, University Diponegoro.

Sanders, M. R., \& Morawska A.(2005). Can changing parental knowledge, dysfunctional expectations and attributions, and emotion regulation improve outcomes for children?. In: Tremblay RE, Barr RG, Peters RDeV, eds. Encyclopedia on Early Childhood Development [online]. Montreal, Quebec: Centre of Excellence for Early Childhood Development. Available at: http://www.childencyclopedia.com/documents/SandersMorawskaANGxp.pdf

Seran, N., Christina, D., Connie, M., \& Marcia, D. (2013). Parenting style and oral health status. Journal of pediatric, 3, 188-194

Sharma, V., Gupta, N., Arora, V., Gupta, P., \& Mehta, N. (2015). Caries experience in permanent dentition among 11-14 years old school children in Panchkula district (Haryana) India. Int J Sci Study, 3(1), 112-5.

Sogi, H. S., Hugar, S. M., Nalawade, T. M., Sinha, A., Hugar, S., \& Mallikarjuna, R. M. (2016). Knowledge, attitude, and practices of oral health care in prevention of early childhood caries among parents of children in Belagavi city: A Questionnaire study. Journal of family medicine and primary care, 5(2), 286.

Sufia, S., Chaudhry, S., Izhar, F., Syed, A., Qayum Mirza, B. A., \& Ali Khan, A. (2011). Dental Caries Experience in Preschool Children-Is It Related to A Child's Place of Residence and Family Income?. Oral Health and Preventive Dentistry, 9(4), 375.

Suseno, D. D. (2010). Hubungan Antara Pola Asuh Orang Tua dengan Kemandirian Anak Usia Prasekolah di TK Aisyiyah Mendungan Sukoharjo. Skripsi. Surakarta: Fakultas IImu Kesehatan, Universitas Muhammadiyah Surakarta.

Supartini, Y. (2004). Buku Ajar Konsep Dasar Keperawatan Anak. Jakarta: EGC.

Warni, L. (2009). Hubungan perilaku murid SD kelas V dan VI pada kesehatan gigi dan mulut terhadap status karies gigi di wilayah Kecamatan Delitua Kabupaten Deli Serdang tahun 2009. Tesis. Medan: Fakultas Kesehatan Masyarakat, Universitas Sumatra Utara.

Worang, T. Y., Pangemanan, D. H., \& Wicaksono, D. A. (2014). Hubungan tingkat pengetahuan orang tua dengan kebersihan gigi dan mulut anak di TK Tunas Bhakti Manado. e-GiGi, 2(2). 